\title{
Improvement of the Vitrification Method Suppressing the Disturbance of Meiotic Spindle and Chromosome Systems in Mature Oocytes
}

\author{
Yun Jin Jung and ${ }^{\dagger}$ Yong-Pil Cheon \\ Division of Developmental Biology and Physiology, School of Biosciences and Chemistry, Institute of Basic Science, \\ College of Natural Sciences, Sungshin Women's University, Seoul 142-732, Republic of Korea
}

\begin{abstract}
Vitrification method is widely used in oocyte cryopreservation for IVF but the birth rates are lower than that of the fresh oocyte. One of the known main reasons is structural instability of meiotic spindle and chromosome systems of mature oocyte. To get the best way for keeping competence of matured oocytes, we studied the best conditions for vitrification focused on equilibration times. The mature oocytes were underwent vitrification with current popular method and analyzed the survival rates, microtubule stability and DNA integrity. The survival rates of recovered oocyte are almost same between groups and are more than $93 \%$. The structural configuration of meiotic spindle was well kept in 10 min equilibration group and the stability rate was almost same with that of control. The chromosomal breakdown was observed in all experimental groups, but the chromosomal stability was higher in 10 min equilibration group than the other groups. The 10 min equilibration group showed best condition compared with the other groups. Based on these results, the equilibration time is one of the key factors in successful keeping for competence of mature oocyte. Although, more fine analysis about the effects of physical stress on oocyte during vitrification is needed to define the optimal condition, it is suggested that the optimal equilibration time to get competent oocyte in mouse is $10 \mathrm{~min}$. Information acquired this study may provide insight into intracellular structural events occurring in human oocytes after vitrification and application for cryopreservation of human oocyte.
\end{abstract}

Key words : Cryopreservation, Vitrification, Chromosome, Meoitic spindle, Matured oocyte

\section{INTRODUCTION}

How maintain or improve the fertility of male or female is one of the main interestings in development and reproductive biology. The methods for preservation of sperm, oocyte, embryo and reproductive tissue has been developed recently. Oocyte cryopreservation has more wide clinical implications than embryos freezing procedure (Wennerholm,
2000) because women who have no partner or have the possibility to lose their ovarian function due to surgery, chemotherapy or radiotherapy can store their oocytes for future use. Cryopreservation of the excess oocytes can avert the repeated ovarian stimulation and oocyte collection in women undergoing in-vitro fertilization (IVF) or can be a source for oocyte donation. It also gives more chance for women to achieve their social goal and provide more

\footnotetext{
Manuscript received 15 May 2014, Received in revised form 22 May 2014, Accepted 30 May 2014

${ }^{\dagger}$ To whom correspondence should be addressed : Yong-Pil Cheon, Division of Developmental Biology and Physiology, School of Biosciences and Chemistry, Institute of Basic Science, College of Natural Sciences, Sungshin University, 147 Mia-dong, Kangbuk-gu, Seoul 142-732, Korea. Tel. : +82-2920-7639, Fax : +82-2-920-2047, E-mail : ypcheon@sungshin.ac.kr

This is an Open Access article distributed under the terms of the Creative Commons Attribution Non-Commercial License (http:// creativecommons.org/licenses/by-nc/3.0) which permits unrestricted non-commercial use, distribution, and reproduction in any medium, provided the original work is properly cited.
} 
reproductive choices because oocyte storage allows women to preserve the fertility for the future. Oocyte cryopreservation therefore has the potential to be an important adjunct to ART in human and other mammals. However, there has been the relatively limited preservative of mature oocyte (Veeck, 2003; Borini et al., 2004) compared with that of embryos (Mandelbaum et al., 1998).

Mature oocytes stay in metaphase block during secondary meiotic division in mammals including human. At this stage, the chromatins are condensed and become chromosome, and made specific connection with the metaphase $\Pi(\mathrm{M} \Pi)$ spindles. A spindle apparatus is a dynamic conglomerate of microtubules and associated structural proteins, acting to coordinate cytokinetic and karyokinetic events essential for normal chromosome segregation. First meiotic division is completed by cooperation of cytoskeletons, especially microfilaments and microtubules. Cytoskeleton is a key factor to get the successfully competent oocytes. Until sperm entry, the matured oocytes stay in metaphase block. This block is accomplished by stable spindle and other regulators for cell cycle. As oocytes transit into metaphase, microtubules change from radial arrays to an organized barrel-shaped bipolar structure containing a blend of dense material at either pole known as microtubules organizing centers (MTOCs).

The most important things are keeping the structural stability of both spindle and chromosomes for developmental competence. Unfortunately, many reports, however, have demonstrated that cryopreservation of oocytes may cause depolymerization and disorganization of spindle microtubules (Pickering \& Johnson, 1987; Vincent et al., 1989; Aman \& Parks, 1994). Oocytes are exposed to many stresses including thermal, mechanical and chemical stress during process of cryopreservation and caused the lost of survivability (Meryman, 1971; Mazur et al., 1972). In fact, the process of cryopreservation of meiotic spindles is leading to impairment of fertilization of such oocytes and the growth of embryos (Aman \& Parks, 1994; Eroglu et al., 1998).

There are two methods that are used to cryopreserve the mamalian oocytes, slow-freezing and vitrification (Bernard \& Fuller, 1996). High survival rates of human oocytes following slow-freezing have been achieved with sodium depleted medium and/or elevated sucrose concentrations (Fabbri et al., 2001; Bianchi et al., 2005; Borini et al., 2006; Stachecki et al., 2006). However, despite the increase in survival rates, implantation rates are still low; between 12$14 \%$ per transferred embryo (Boldt et al., 2006; Oktay et al., 2006). Recently, vitrification has been widely used for cryopreservation of ovine, equine, murine, rabbit, bovine, and porcine embryos at all stage of embryonic development, including blastocyst stages, and oocyte. It is suggested that vitrification may be more effective than slow-freezing (Kuleshova \& Lopata, 2002), resulting in improved oocyte survival and pregnancy rates (Yoon et al., 2003; Katayama et al., 2003; Lucena et al., 2006).

Vitrification is a process that produces a glasslike solidification of living cells that completely avoids ice crystal formation during cooling and warming (Al-Hasani et al., 1986; Diedrich et al., 1988). However, a major concern of vitrification relates to the use of higher concentration of membrane-permeable cryoprotectants (CPA) in the suspending solution, such as dimethyl sulfoxide (DMSO), 1,2-propanediol (PROH), and/or ethylence glycol (EG). It has been known that exposure time to the high concentration of cryoprotectants during vitrification is one of the main factors influencing the oocytes. Therefore in this study, the stability of meiotic organelles was examimed to evaluate the vitrification influences on the survival of mature oocyte. In addition, cryoinjury of oocytes was detected at DNA level during vitrification.

MATERIALS AND METHOD 


\section{Mature oocytes collection}

All animals involved in this study were approved by the Animal Care Committee and studies were conducted for the Care and Use of Laboratory. To get MII stage oocyte, the female mice were injected with $5 \mathrm{IU}$ of pregnant mares serum gonadotropin (PMSG; Folligon, Intervet) followed by injection with 5 IU of human chrionic gonadotropin (hCG) in 48 hrs later (i.p.). After $15 \mathrm{~h}$ of hCG injection, the mice were sacrificed and the oviducts were dissected and placed into a dish containing Quinn's Advantage ${ }^{\mathrm{TM}}$ Medium with HEPES (Sage Biopharma, San Clemente, CA; cat. no. 1023) supplemented with $1.0 \mathrm{mg} / \mathrm{mL}$ bovine serum albumin (BSA) (Sigma, A8022). The cumulus-oocyte complexes (COC) were released by tearing the ampullae of the oviduct. The cumulus mass were removed using both hyaluronidase (80 IU/mL) (Sigma, H3506) and mechanical force using a fine glass pipette. The denuded oocytes were washed several times with Quinn's Advantage ${ }^{\mathrm{TM}}$ Medium with HEPES supplemented with $1.0 \mathrm{mg} / \mathrm{mL}$ BSA at RT and undergone for next examination.

\section{Vitrification of mature oocyte}

Oocytes were cryopreserved by vitrification methods as described by Kuwayama and his colleagues (2005) with minor modifications. The solution for vitrification and warming was PBS containing cryoprotectants and 10\% serum protein substitute. The equilibration solution consisted of 7.5\% ethylene glycol (EG; Sigma E9129) and 7.5\% dimethyl sulfoxide (DMSO; Sigma D5879). The vitrification solution consisted of 15\% EG and 15\% DMSO, $0.5 \mathrm{M}$ sucrose (S; Sigma S7903). The oocytes were placed in 7.5\% ethylene glycol EG and 7.5\% DMSO for 5, 10 and $15 \mathrm{~min}$. Then those were transferred into the vitrification solution $(15 \% \mathrm{EG}+15 \% \mathrm{DMSO}+0.5 \mathrm{M}$ sucrose $)$. After 40 60 sec of exposure in the vitrification solution, oocytes were loaded onto straw (Fig. 1) and directly plunged into liquid nitrogen $\left(\mathrm{LN}_{2}\right)$.
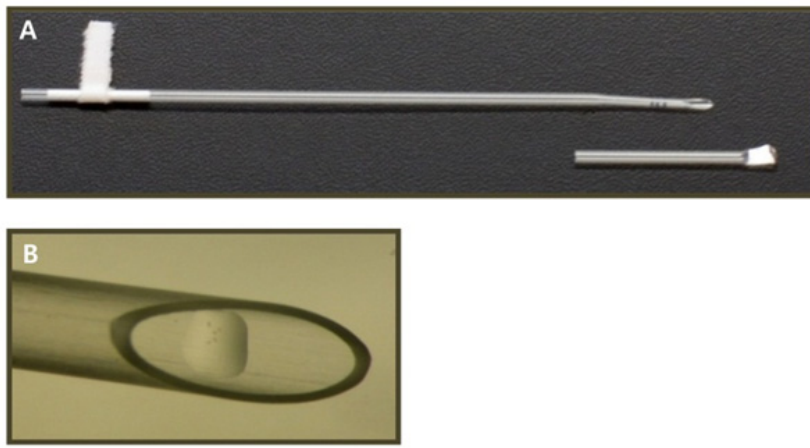

Fig. 1. Device for vitrification of oocyte. A. Cryo vessel (modied straw). B. Photographs showing the loaded oocytes.

After being stored in $\mathrm{LN}_{2}$ for at least 1 week, warming was accomplished holding the frozen straw for $10 \mathrm{sec}$ at $37^{\circ} \mathrm{C}$. Oocytes were sequentially rehydrated in PBS containing 1 $\mathrm{M}$ sucrose for $1 \mathrm{~min}$ at $37^{\circ} \mathrm{C}$ and $0.5 \mathrm{M}$ sucrose for $3 \mathrm{~min}$ at RT and rinsed twice in PBS for $5 \mathrm{~min}$, respectively. And then the oocytes were transfered back into the culture medium and cultured for an additional $1 \mathrm{hr}$.

\section{Morphological assessment of oocytes after warming}

Oocytes were defined as having morphologically survived if the oocytes possessed an intact zona pelludia and plasma membrane and refractive cytoplasm. They were counted and recorded.

\section{Evaluation of meiotic spindle and chromosome in oocytes}

Tubulin and chromatin were stained by immunofluorescent staining, as described previously (Jack et al., 2007). Briefly, after warming the oocytes were incubated for $1 \mathrm{hr}$ at $37^{\circ} \mathrm{C}$ in $5.0 \% \mathrm{CO}_{2}$ incubator. Then the warmed oocytes were fixed in 4\% paraformaldehyde for 5 minutes. After fixation, the oocytes were washed extensively in PBS and blocked overnight at $4^{\circ} \mathrm{C}$ in blocking medium (PBS, supplemented with $0.02 \% \mathrm{NaN}_{3}, 0.2 \%$ non-fat dry milk, $2 \%$ goat serum, $2 \% \mathrm{BSA}$ and $0.1 \mathrm{moL} / \mathrm{L}$ glycine). After rinsing in PBS, the oocytes were incubated with $\beta$-tubulin monoclonal antibody 
(Sigma F2043) diluted $1: 150$ in PBS at $4^{\circ} \mathrm{C}$ overnight. After then, oocyte washed several times with PBS and incubated with fluorescein isothiocyanate (FITC)- conjugated anti-mouse IgG (Sigma F5387) diluted 1:150 in PBS for $60 \mathrm{~min}$ at $37^{\circ} \mathrm{C}$. After washing with PBS for several times, the samples were mounted onto a slide under a cover slip in the Vectashield mounting medium (Vector Laboratories, Burlingame, CA), containing 4,6-diamidino-2-phenylindole (DAPI).

\section{Comet assay in vitrified oocytes}

Morphologically intact oocytes underwent comet assay to detect cryoinjury at DNA level. The individual oocytes were employed for comet assay that was carried out as previously described (Singh et al., 1988). All products for comet assay were obtained from Trevigen, Inc (Gaithersburg, MD). Quantitative analysis of DNA damage included the counting the number of oocytes with the presence of a comet tail.

\section{Statistics}

The $t$-test was used to evaluate the difference between controls and experiment groups. Results were presented as $\mathrm{MEAN} \pm \mathrm{SD}$. A $p$-value less than 0.05 were considered to be a significant difference.

\section{RESULTS}

1. Change the volume of oocyte during equilibration and vitrification

The volumatric changes were recored during vitrifycation (Fig. 2). At the time of equilibration, within $1 \mathrm{~min}$ after expose to dehydration solution the oocytes were shrunk (Fig. 2B) and got equilibration from $10 \mathrm{~min}$ (Fig. 2C, D). After treatment with vitrification solution for 40 sec, there was dramatic shrinking of the equlibrated oocytes (Fig. 2E).

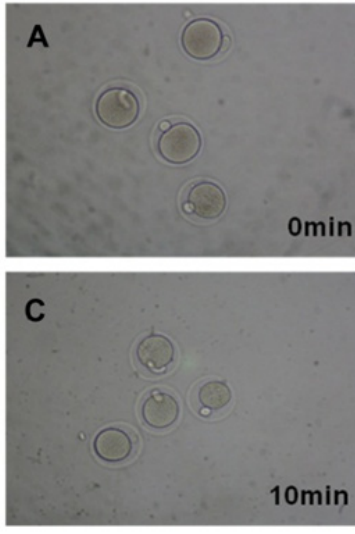

E

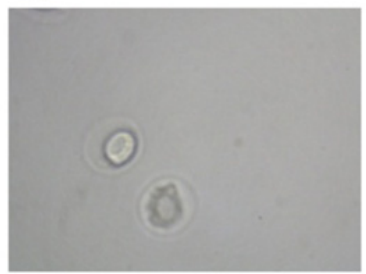

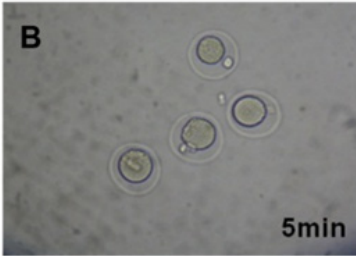

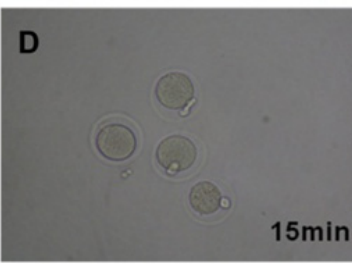

$\mathbf{F}$

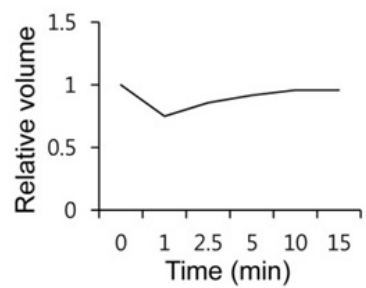

Fig. 2. Photomicrograph of subjected oocytes during dehydration and equilibration periods. $\mathrm{A}, \mathrm{B}, \mathrm{C}$ and $\mathrm{D}$ showed $0 \mathrm{~min}, 5 \mathrm{~min}, 10 \mathrm{~min}$ and $15 \mathrm{~min}$ oocytes after treatment of equilibration solution, respectively. $\mathrm{E}$ is shown the oocytes which is treated in vitrification solution. $\mathrm{F}$ is shown the volume changes of oocytes during equilibration time.

\section{Morphological assessment of oocyte survival} after warming

A total 445 oocytes were vitrified. After warming and washing, oocytes were assessed for cryosurvival according to the criteria mentioned in Materials and Methods (Fig. 3). Survival rates of the recovered oocytes were higher than $90 \%$ and there was no difference between experimental groups. MII oocytes after vitrification and warming were morphologically indistinguishable compared to them before cryopreservation. The recovered oocytes had normal-appearing zona pellucidae, intact polar bodies, normal perivitelline spaces, intergral plasma membranes, and normal-appearing evenly granular cytoplasm. After $1 \mathrm{hr}$ of culture, the survival rates were $97.1 \%(102 / 105)$ and $93.5 \%(174 / 186)$ and $95.5 \%(147 / 154)$ for 5,10 , and $15 \mathrm{~min}$, respectively 

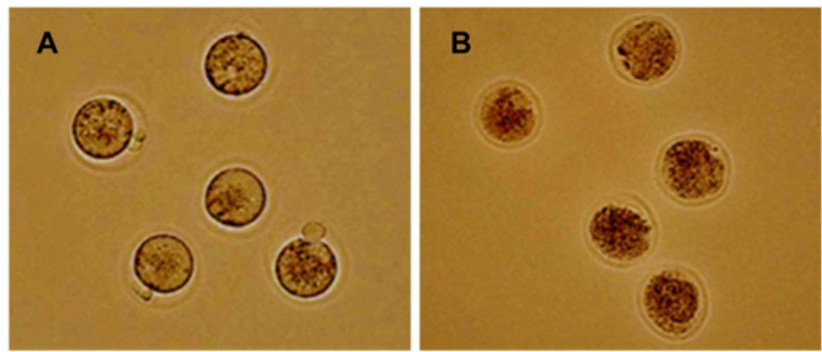

Fig. 3. Photomicrograph of survived or damaged oocytes after vitrfication-warming. A showed survived oocyte and B showed damaged oocytes.

Table 1. Effect of the pre-equilibration time on survival rates of recovered oocytes after vitrification and warming of mature oocytes

\begin{tabular}{ccc}
\hline \hline $\begin{array}{c}\text { Time } \\
(\mathrm{min})\end{array}$ & $\begin{array}{c}\text { No. of } \\
\text { vitrified oocytes }\end{array}$ & $\begin{array}{c}\text { Survival rate } \\
(\%)\end{array}$ \\
\hline 5 & 105 & $102 / 105(97.1 \%)$ \\
10 & 186 & $174 / 186(93.5 \%)$ \\
15 & 154 & $147 / 154(95.5 \%)$ \\
\hline
\end{tabular}

(Table 1). From those results, the device for vitrification and time point were good to keep the viability of oocytes.

\section{Analysis of spindle and chromosome configuration}

Morphological analysis is not enough to prove the stability of competency of matured oocytes. So we analyzed the stability of spindle and chromosome. The spindle morphology and chromosomal patterns of vitrified oocytes of $1 \mathrm{hr}$ incubation in $5 \% \mathrm{CO}_{2}$, in air at $37^{\circ} \mathrm{C}$. The majority of the recovered oocytes maintained the normal meiotic spindle morphology and chromosome alignment (Fig. 4).

The rates of oocyte having normal spindle and chromosomal configuration were $74.3 \%, 81.1 \%$ and $66.3 \%$ in 5 min group, 10 min group, and 15 min group, respectively. In control group which were collected after superovulation, the rate of normal spindle and chromosomal arrangement was $87 \%$. Compared to the control group, there were no significant difference in $5 \mathrm{~min}$ and $10 \mathrm{~min}$ group, but there was a significant decrease in 15 min group (Table 2).
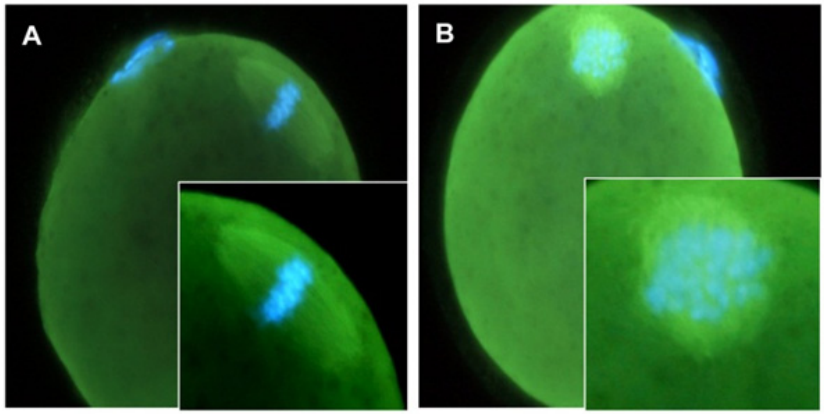

Fig. 4. Photomicrograph of meiotic spindle and organization and chromosome alignment in mature oocytes after vitrification and warming. A, Oocyte with normal meiotic spindle organization and chromosome alignment. B, Oocyte with abnormal meiotic spindle organization and chromosome alignment.

Table 2. Morphological stability of meiotic spindle and chromosome in mature oocytes after vitrificationwarming

\begin{tabular}{cccc}
\hline \hline \multirow{2}{*}{$\begin{array}{c}\text { Equilibration } \\
\text { time }\end{array}$} & $\begin{array}{c}\text { No. of } \\
\text { oocyte }\end{array}$ & \multicolumn{2}{c}{$\begin{array}{c}\text { Spindle and chromosome } \\
\text { configuration (\%) }\end{array}$} \\
\cline { 2 - 4 } & & Normal & Abnormal \\
\hline Control & 69 & $60(87.0)$ & $9(13.0)$ \\
5 min & 77 & $57(74.3)^{\mathrm{a}}$ & $20(25.7)$ \\
$10 \mathrm{~min}$ & 90 & $73(81.1)$ & $17(18.9)$ \\
$15 \mathrm{~min}$ & 83 & $55(66.3)^{\mathrm{a}, \mathrm{b}}$ & $28(33.7)$ \\
\hline
\end{tabular}

a: $p<0.05$ control vs. experimental group

b: $p<0.055$ and 10 groups vs. 15 groups

The 10 min equilibration gave more stability signifycantly than the other groups. Compared with control and 10 min group, the stability did not change (Table 2). However, the stability of spindle and chromosomal configuration was significantly decreased in $5 \mathrm{~min}$ and $15 \mathrm{~min}$ group compared to 10 min group.

\section{DNA fragmentation of vitrified and warmed oocyte}

One of the well established method for the analysis of the chromosomal stability is comet method and it was applied after morphological analysis (Fig. 5). In control group, the oocytes which had comet tail were $15.3 \%$ but 

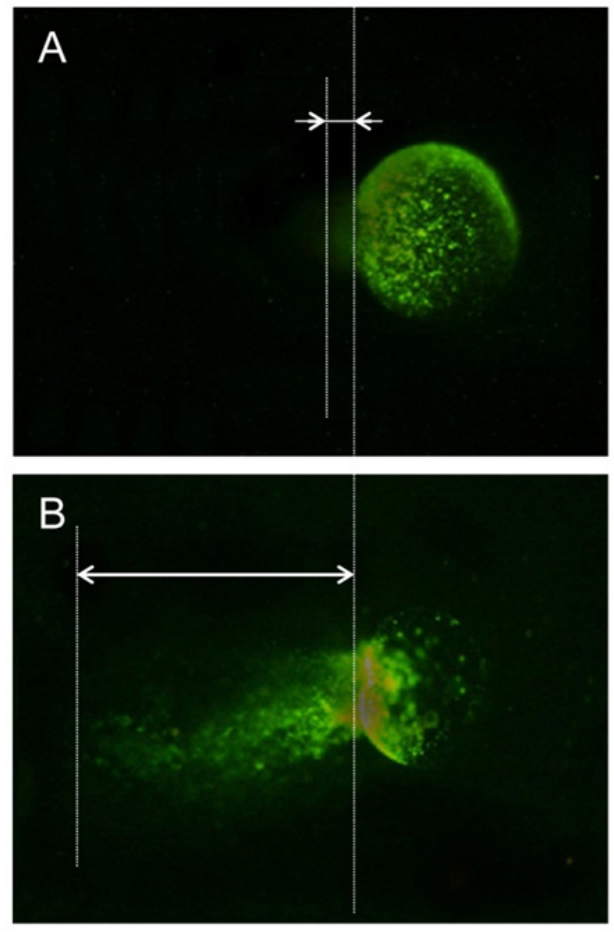

Fig. 5. DNA fragmentation analysis of the mouse oocytes based on the comet tail. DNA of the Oocyte shows no fragmentation (A) and the fragmented DNA of the oocyte has migrated out from the membrane (B). The direction of electophoresis is from right to left and the comet tail containing the DNA fragments that was stained by SYBR green.

Table 3. Analysis of DNA fragmentation after vitrifycation by comet assay

\begin{tabular}{ccc}
\hline $\begin{array}{c}\text { Equilibration } \\
\text { time }\end{array}$ & $\begin{array}{c}\text { No. of } \\
\text { oocytes }\end{array}$ & $\begin{array}{c}\text { No. of oocytes } \\
\text { with comet tail (\%) }\end{array}$ \\
\hline Control & 13 & $2(15.3)$ \\
$5 \mathrm{~min}$ & 14 & $6(42.9)^{\mathrm{a}}$ \\
$10 \mathrm{~min}$ & 16 & $7(43.8)^{\mathrm{a}}$ \\
$15 \mathrm{~min}$ & 15 & $12(73.3)^{\mathrm{a}, \mathrm{b}}$ \\
\hline
\end{tabular}

a: $p<0.05$ control vs. experimental group

b: $p<0.055$ and 10 groups vs. 15 groups

the percent of comet tail was increased dramatically in the cryopreserved oocytes (Table 3).

As shown in Table 3, the percentage of oocytes with comet tails was significantly higher $(P<0.05)$ in $15 \mathrm{~min}$ group compared to 5 min exposure group. However, there were no difference in the percentage of oocytes with comet tails between $5 \mathrm{~min}$ exposure group oocytes and $10 \mathrm{~min}$ exposure group.

\section{DISCUSSION}

A major advantage of vitrification is the elimination of mechanical damage caused by intra- or extra-cellular ice crystals and potential reduction of chilling damage by shortening the exposure to suboptimal temperatures. However, vitrification is a result of high cooling rates associated with high concentrations of cryoprotectants. If used incorrectly, these cryoprotectants can be toxic. Therefore, vitrification necessitated the reduced and precise exposure times and rapid movement of cells through solution.

An important problem with oocyte cryopreservation is the variable survival rate (Chen, 1986; Porcu et al., 1997; Boldt et al., 2003; Fosas et al., 2003). Modified slowfreezing methods have improved survival rates (Fabbri et al., 2001; Fosas et al., 2003; Bianchi et al., 2005; Borini et al., 2006; Stachecki et al., 2006), but as yet it is still unclear as to which method provides the best overall success. However, it is suggested that vitrification has advantages in varios points compared with slow-freezing. In this study, the survival rates of recovered oocytes are almost same between groups and are higher than $93 \%$. The suvival rate was higher previously reports which employed vitrification and other freezing methods (Huang et al., 2008).

At the time of ovulation, the oocyte is arrested at MII stage of meiosis with the chromosomes aligned at the equatorial plate of the meiotic spindle and the first polar body extruded. The completion of meiosis depends on the presence of intact spindle microtubules to achieve normal segregation of the chromatids. Spindle microtubules consist of polymerized tubulin, the major component of spindle 
microtubules, in equilibrium with the free tubulin pool within the oolemma (Vincent \& Johnson, 1992). The dynamic equilibrium between polymerized and free tubulins in mammalian oocytes is extremely sensitive to temperature change (Zenses et al., 2001). Cooling of mouse oocytes causes tubulin to undergo depolymerization and results in the disappearance of microtubule organizing centers (Magistrini \& Szollosi, 1980; Webb et al., 1986; Pickering \& Johnson, 1987). In addition, exposure of human and animal oocytes to cryoprotectant can induce spindle alterations and chromosomal anomality (Van Elast et al., 1988; Sathananthan et al., 1988; Pickering, 1990). Based on the morphological analysis of spindle microtuvules and chromosome, normal rate of spindle and chromosome configuration was significantly high in 10 min equlibration time group compared with the other groups.

Surprisingly the chromosomal breakdown was severe in the recovered oocytes in all experimental groups. The chromosomal stability was kept well in 10 min equilibration group compared with the other groups. The $10 \mathrm{~min}$ equilibration group showed best condition compared with the other groups, but the rate was less than $56 \%$. Therefore, to improve the stability of chromosome, more fine analysis about the effects of physical stress on oocyte during vitrification is needed to define the optimal condition, it is suggested that the optimal equilibration time to get competent oocyte in mouse is $10 \mathrm{~min}$.

The survival rate was higher than those of the previous reports independently to the equilibration times. In addition, the normal rate of spindle and chromosome configuration was improved by changing the equlibration time. However, the stability of DNA was not dramatially improved. Based on these results, it is suggested that the equilibration time is one of the key factors in successful ekeeping for competence of mature oocyte. Information acquired this study with mouse oocyte may provide insight into intracellular structural events occurring in human oocytes after vitrify- cation and application for cryopresevation of human or other mammals oocytes.

\section{ACKNOWLEDGEMENT}

This work was supported by the Sungshin Women's UnJeong Global Project research Grant of 2013 and we thanks to the support of Seung Jae Lee, director of Mireawaheemang hospital.

\section{REFERENCES}

Aman R, Parks J (1994) Effects of cooling and rewarming on the meiotic spindle and chromosomes of in vitro matured bovine oocytes. Biol Reprod 50:103-110.

Al-Hasani S, Diedrich K, Van der Ven H, Krebs D (1986) Initial results of the cryopreservation of human oocytes. Geburtshilfe Frauenheikd 46:643-644.

Bernard A, Fuller B (1996) Cryopreservation of human oocytes: a review of current problems and perspectives. Hum Reprod Update 2:193-207.

Bianchi V, Coticchio G, Fava L, Flamigni C, Borini A (2005) Meiotic spindle imaging in human oocytes frozen with a slow freezing procedure involving high sucrose concentration. Hum Reprod 220:1078-1083.

Boldt J, Cline D, McLaughlin D (2003) Human oocyte cryopreservation as an adjunct to IVF-embryo transfer cycles. Hum Reprod 18:1250-1255.

Boldt J, Tidswell N, Sayears A, Kilani R, Cline D (2006) Human oocyte cryopreservation: 5-year experience with a sodium-depleted slow freezing method. Reprod Biomed online 13:96-100.

Borini A, Bonu MA, Coticchio G, Bianchi V, Cattoli M, Flamigni C (2004) Pregnancies and births after oocyte cryopreservation. Fertil Steril 82:601-605.

Borini A, Sciajno R, Bianchi V, Sereni E, Flamigni C, Coticchio G (2006) Clinical outcome of oocyte cryo- 
preservation after slow cooling winchith a protocol utilizing a high sucrose concentration. Hum Reprod 21:512-517.

Chen C (1986) Pregnancy after human oocyte cryopreservation. Lancet 1:884-886.

Diedrich K, Al-Hasani S, Van der Ven D (1988) Successful in vitro fertilization of frozen-thawed rabbit and human oocytes. Ann NY Acad Sci 541:562-570.

Eroglu A, Toth TL, Toner M (1998) Alterations of the cytoskeleton and polyploidy induced by cryopreservation of metaphase II moue oocytes. Fertil Steril 69:944957.

Fabbri R, Porcu E, Marsella T, Rocchetta G (2001) Human oocyte cryopreservation: new perspectives regarding oocyte survival. Hum Reprod 16:411-416.

Fosas N, Marina F, Torres PJ, Jove I, Martin P, Perez N, Arnedo N, Marina S (2003) The births of five spanish babies from cryopreserved donated oocytes. Hum Reprod 18:1417-1421.

Huang YJ, Chen HY, Park JY, Tan SL, Chian RC (2008) Comparison of spindle and chromosome configuration in in vitro- and in vivo-matured mouse oocytes after vitrification. Fertil Stertil 90:1424-1432.

Katayama KP, Stehlik J, Kuwayama M, Kato O, Stehlik E (2003) High survival rate of vitrified human oocytes results in clinical pregnancy. Fertil Steril 80:223-224.

Kuleshova LL, Lopata A (2002) Vitrification can be more favorable than slow cooling. Fertil Steril 78:44-54.

Kuwayama M, Vajta G, Ieda S, Kato O (2005) Comparison of open and closed methods for vitrification of human embryos and the elimination of potential contamination. Reprod Biomed Online 11:608-614.

Lucena E, Bernal DP, Lucena C, Rojas A, Moran A, IUCENA A (2006) Successful ongoing pregnancies after vitrification of oocytes. Fertil Stertil 85:108-111.

Magistrini M, Szollosi D (1980) Effects of cold and of isopropyl-N-phenylacarbamate on the second meiotic spindle of mouse oocytes. Eur J Cell Biol 22:699-707.

Mazur P, Leibo S, Chu E (1972) A two-factor hypothesis of freezing injury: evidence from Chineses hamster tissue-culture cells. Exp Cell Res 71:345-355.

Mandelbaum J, Belaisch-Allart J, Junca AM, Antoine JM, Plachot M, Alvarez S, Alnot MO, Salat-Baroux J (1998) Cryopreservation in human assisted reproduction is now routine for embryos but remains a research procedure for oocytes. Hum Reprod 13:161-174.

Meryman HT (1971) Cryoprotective agents. Cryobiology $8: 173-83$

Oktay K, Cil AP, Bang H (2006) Efficiency of oocyte cryopreservation a meta-analysis. Fertil Steril 86:70-80.

Pickering SJ, Braude PR, Johnson MH, Cant A, Currie J (1990) Transient cooling to room temperature can cause irreversible disruption of the meiotic spindle in the human oocyte. Fertil Stertil 54:102-108.

Pickering S, Johnson M (1987) The influence of cooling on the organization of the meiotic spindle of the mouse oocytes. Hum Reprod 2:207-216.

Porcu E, Fabbri R, Seracchioli R, Ciotti PM, Magrini O, Flamigni C (1997) Birth of a healthy female after intracytoplasmic sperm injection of cryopreserved human oocytes. Fertil Steril 68:724-726.

Sathananthan AH, Ng SC, Trounson AO, Bongso A, Ratnam SS, Ho J, Mok H, Lee MN (1988) The effects of ultrarapid freezing on meiotic and mitotic spindles of mouse oocytes and embryos. Gamete Res 21:385-401.

Singh NP, McCoy MT, Tice RR, Schneider EL (1988) A simple technique for quantitation of low levels of DNA damage in individual cells. Exp Cell Res 175:184-191.

Stachecki JJ, Cohen J, Garrisi J, Munne S, Burgess C, Willadsen SM (2006) Cryopreservation of unfertilized human oocytes. Reprod Biomed Online 13:222-227.

Veeck LL (2003) Does the developmental stage at freeze impact on clinicla results post-thaw? Reprod Biomen Online 6:367-374. 
Vincent C, Garnier V, Heyman Y, Renard J (1989) Solvent effects on cytoskeletal organization and in-vivo survival after freezing of rabbit oocytes. J Reprod Fertil 87:809820.

Vincent C, Johnson MH (1992) Cooling, cryoprotectants, and the cytoskeleton of the mammalian oocyte. Oxford Rev Reprod Biol 14:73-100.

Webb M, Howlett SK, Maro B (1986) Parthenogenesis and cytoskeletal organization in agein mouse eggs. J Embryol Exp Morphol 95:131-145.

Wennerholm WB (2000) Cryopreservation of embryos and oocytes:obstetric outcome and health in children. Hum Reprod 15:18-25.

Yoon TK, Kim TJ, Park SE, Hong SW, Ko JJ, Chung HM, Cha KY (2003) Live births after vitrification of oocytes in a stimulated in vitro fertilization-embryo transfer program. Fertil Steril 79: 1323-1326.

Zenses MT, Bielecki R, Casper R, Leibo SP (2001) Effects of chilling to $0^{\circ} \mathrm{C}$ on the morphology of meiotic spindles in human metaphase II oocytes. Fertil Steril 75:769777. 